\title{
When and How to Combine Antiplatelet and Anticoagulant Drugs?
}

\author{
Christine Espinola-Klein ${ }^{1}$ \\ ${ }^{1}$ Center of Cardiology, Cardiology III - Angiology, University Medical \\ Center of the Johannes Gutenberg-University, Mainz, Germany \\ Hamostaseologie 2022;42:73-79.
Address for correspondence Prof. Dr. med. Christine Espinola-Klein, Department of Cardiology, Cardiology III - Angiology, University Medical Center of the Johannes Gutenberg-University, Langenbeckstrasse 1, 55131 Mainz, Germany (e-mail: espinola@uni-mainz.de).

Abstract
Keywords
- antiplatelet drugs
- anticoagulant drugs
- bleeding risk
- thrombotic risk
- prognosis

Antiplatelet and anticoagulant drugs work at different places in the coagulation system. Antiplatelet drugs are usually indicated in patients with atherosclerosis. Anticoagulant drugs are mostly used in patients with atrial fibrillation, venous thromboembolism, or technical heart valves. In some clinical situations, combination of antiplatelet and anticoagulant therapy can be indicated. The most recent situations are a more intensive antithrombotic therapy for risk reduction in patients with atherosclerosis and temporary addition of antiplatelet drugs in patients with indication for long-term anticoagulation. Temporary combination of antiplatelet and anticoagulant drugs is usually necessary after coronary intervention in patients with atrial fibrillation. In patients with high-risk atherosclerosis, the combination of low-dose rivaroxaban and aspirin reduces major adverse cardiovascular events (myocardial infarction, stroke, cardiovascular death) and major adverse limb events. But every combination of antiplatelet and antithrombotic drugs can increase bleeding risk. Therefore, a careful assessment of thrombotic versus bleeding risk is necessary for each patient.

\section{Introduction}

Blood coagulation is a very complex system. Platelet activation and aggregation as well as fibrin generation are crucial in this process. Drugs such as aspirin, clopidogrel, prasugrel, and ticagrelor are inhibitors of platelet aggregation. Vitamin $\mathrm{K}$ antagonists (VKAs), factor $\mathrm{X}$ inhibitors (apixaban, edoxaban, rivaroxaban), and dabigatran inhibit fibrin generation. However, we have to keep in mind that every intervention on one side has side effects on other side ( - Fig. 1 ).

Antiplatelet and anticoagulant drugs are used in different indications and dosages. Usually, anticoagulant drugs are necessary in patients with venous thromboembolism or atrial fibrillation. In these indications, therapeutic dosage of anticoagulants is necessary. When VKAs are used, dosage is assessed according to international normalized ratio (INR). Usually, a range of 2 to 3 in venous thromboembolism or atrial fibrillation is indicated. In these indications, factor Xa inhibitors (rivaroxaban: $20 \mathrm{mg}$ od, apixaban: $5 \mathrm{mg}$ bd, edoxaban: $60 \mathrm{mg}$ od) or thrombin antagonists (dabigatran: 110 or $150 \mathrm{mg}$ bd) are used in standardized dosage if there is no renal insufficiency. In patients with atherosclerosis of coronary or peripheral arteries, usually antiplatelet drugs are used.

Combination of antiplatelet and anticoagulant drugs can be indicated, for example, in high-risk patients with atherosclerosis using low-dose rivaroxaban $(2.5 \mathrm{mg}$ bd $)$ and aspirin. In addition, patients with indication for an anticoagulant may need addition for several months of an antiplatelet after coronary or peripheral intervention. A combination of antiplatelet and anticoagulant drugs can also be discussed in special situations like in patients with severe antiphospholipid antibody syndrome (APS). However, we should always keep in mind that multiple antithrombotic medications lead received

October 10, 2021

accepted after revision

December 15, 2021 (c) 2022. Thieme. All rights reserved. Georg Thieme Verlag KG,

Rüdigerstraße 14,

70469 Stuttgart, Germany
DOI https://doi.org/

$10.1055 / \mathrm{a}-1724-4922$.

ISSN 0720-9355. 

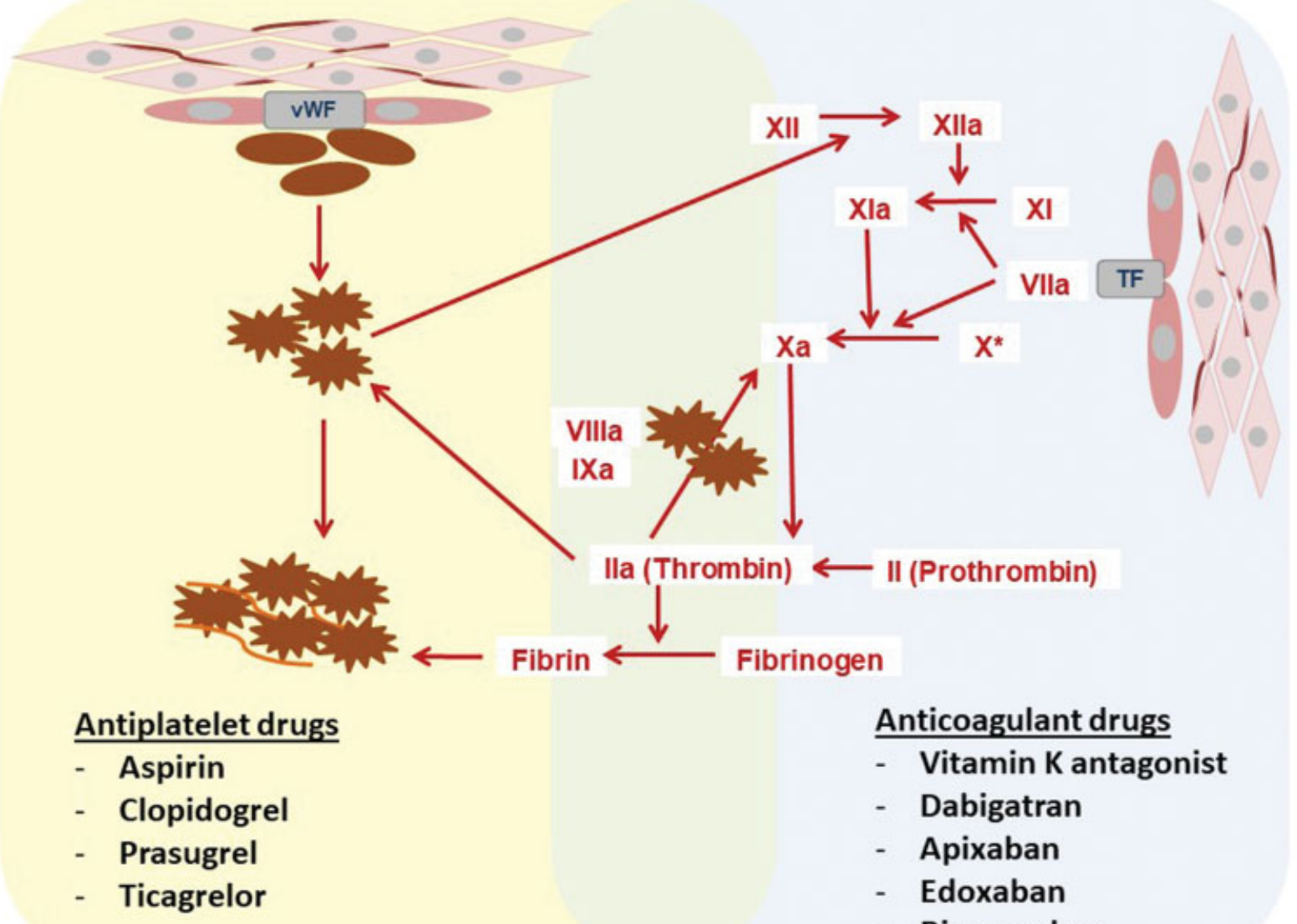

Antiplatelet drugs

- Aspirin

- Clopidogrel

- Ticagrelor

Fig. 1 Effect of antiplatelet and anticoagulant drugs in the coagulation system.

to increased bleeding risk. Therefore, the indication and duration of combined antiplatelet and anticoagulant drugs must be assessed carefully.

This review focuses on the two frequent indications: more intensive antithrombotic therapy for risk reduction in patients with atherosclerosis and temporary therapy with antiplatelet drugs in patients with indication for anticoagulation.

\section{Temporary Therapy with Antiplatelet Drugs in Patients with Indication for Anticoagulation}

Usually, after percutaneous coronary intervention (PCI), dual-antiplatelet therapy is indicated. ${ }^{1,2}$ Duration of dualantiplatelet therapy depends on clinical situation (acute coronary syndrome or chronic coronary artery disease) and procedure-related points (e.g., left main intervention). In particular, patients with acute coronary syndrome need prolongation of intensive antiplatelet therapy.

In some patients undergoing PCI, long-term oral anticoagulation is indicated and should be continued after the intervention because of increased risk for thromboembolic events. Most patients need long-term anticoagulation because of atrial fibrillation; therefore, major randomized trials have been performed including these patients. ${ }^{3}$ In the following section, the main results of randomized controlled trials including patients with $\mathrm{PCI}$ requiring anticoagulation and antiplatelet therapy are summarized ${ }^{4,5}$ ( - Table 1).

Two studies included patients treated with VKA. The WOEST (What is the Optimal antiplatElet \& Anticoagulant Therapy in Patients With Oral Anticoagulation and Coronary StenTing) study was the first randomized trial to address the optimal antiplatelet therapy in patients on oral anticoagulation undergoing coronary stenting. ${ }^{4}$ In total, 573 patients have been included in the trial. Triple antithrombotic therapy (TAT) with VKA, clopidogrel, and aspirin was compared with dual antithrombotic therapy (DAT) with VKA and clopidogrel. Triple therapy resulted in significant higher bleeding risk compared with dual therapy without aspirin. The ISAR-TRIPLE (Intracoronary Stenting and Antithrombotic Regimen-Testing of a 6-Week Versus a 6-Month Clopidogrel Treatment Regimen in Patients with Concomitant Aspirin and Oral Anticoagulant Therapy Following Drug-Eluting Stenting) trial randomized 614 patients to 6 weeks of triple therapy with VKA, aspirin, and clopidogrel followed by VKA and aspirin compared with 6 months of triple therapy with VKA, clopidogrel, and aspirin. ${ }^{5}$ At 9 months, there was no significant difference between the groups with regard to thrombotic or bleeding events. The WOEST and ISAR-TRIPLE study showed in a quite small number of patients that after $\mathrm{PCI}$ and stenting, the combination of VKA with only one antithrombotic drug is not associated with an increase of thrombotic events. 
Table 1 Summary of randomized controlled trials including patients with acute coronary syndrome requiring anticoagulation and antiplatelet therapy according to some studies ${ }^{3-10}$

\begin{tabular}{|c|c|c|}
\hline $\mathrm{RCT}$ & Patient groups & Primary endpoint \\
\hline $\begin{array}{l}\text { WOEST } \\
N=573\end{array}$ & $\begin{array}{l}\text { DAT (VKA + clopidogrel) versus } \\
\text { TAT (VKA + aspirin + clopidogrel) for } 12 \mathrm{mo}\end{array}$ & TIMI bleeding at 1 y lower with DAT vs. TAT \\
\hline $\begin{array}{l}\text { ISAR-TRIPLE } \\
N=614\end{array}$ & $\begin{array}{l}\text { TAT (VKA + aspirin + clopidogrel) for } 6 \mathrm{wk} \\
\text { followed by DAT (VKA + aspirin) versus } \\
\text { TAT (VKA + aspirin + clopidogrel) for } 6 \text { mo }\end{array}$ & $\begin{array}{l}\text { Cardiac death + infarction }+ \text { stent } \\
\text { thrombosis }+ \text { stroke or TIMI major } \\
\text { bleeding at } 9 \text { mo no difference }\end{array}$ \\
\hline $\begin{array}{l}\text { POINEER AF-PCI } \\
N=2,124\end{array}$ & $\begin{array}{l}\text { DAT (rivaroxaban } 15 \mathrm{mg}+\text { clopidogrel) for } 12 \text { mo versus } \\
\text { Modified TAT (rivaroxaban } 2 \times 2.5 \mathrm{mg}+\text { aspirin }+ \text { clopidogrel) } \\
\text { for } 1,6 \text {, or } 12 \text { mo versus } \\
\text { TAT (VKA + aspirin + clopidogrel) for } 1,6 \text {, or } 12 \mathrm{mo}\end{array}$ & $\begin{array}{l}\text { Clinically significant bleeding lower with DAT } \\
\text { or modified TAT vs. TAT }\end{array}$ \\
\hline $\begin{array}{l}\text { RE-DUAL } \mathrm{PCl}^{7} \\
N=2,725\end{array}$ & $\begin{array}{l}\text { TAT (VKA + aspirin + clopidogrel) for up to } 3 \text { mo versus } \\
\text { DAT (dabigatran } 2 \times 110 \text { or } 150 \mathrm{mg}+\text { clopidogrel } \\
\text { or ticagrelor) }\end{array}$ & $\begin{array}{l}\text { Major or clinically relevant non-major bleeding } \\
\text { lower in DAT } 110 \mathrm{mg} \text { or DAT } 150 \mathrm{mg} \text { vs. TAT }\end{array}$ \\
\hline $\begin{array}{l}\text { AUGUSTUS }^{8} \\
N=4,614\end{array}$ & $\begin{array}{l}\text { DAT1 (apixaban } 2 \times 5 \mathrm{mg}+\text { clopidogrel or ticagrelor } \\
\text { or prasugrel) versus } \\
\text { DAT2 (VKA + clopidogrel or ticagrelor or prasugrel) versus } \\
\text { TAT1 (apixaban } 2 \times 5 \mathrm{mg}+\text { aspirin }+ \text { clopidogrel } \\
\text { or ticagrelor or prasugrel) versus } \\
\text { TAT2 (VKA + aspirin + clopidogrel or ticagrelor or prasugrel) }\end{array}$ & $\begin{array}{l}\text { Major or clinically relevant non-major bleeding } \\
\text { lower with DAT1 compared with } \\
\text { DAT2, TAT1, or TAT2 }\end{array}$ \\
\hline $\begin{array}{l}\text { ENTRUST-AF PCl } \\
N=1,506\end{array}$ & $\begin{array}{l}\text { DAT (edoxaban } 60 \mathrm{mg}+\text { clopidogrel or ticagrelor } \\
\text { or prasugrel) versus } \\
\text { TAT (VKA + aspirin + clopidogrel or ticagrelor or prasugrel) }\end{array}$ & $\begin{array}{l}\text { Major or clinically relevant non-major bleeding } \\
\text { non-inferior between DAT or TAT }\end{array}$ \\
\hline
\end{tabular}

Abbreviations: DAT, dual-antithrombotic therapy; RCT, randomized controlled trial; TAT, triple antithrombotic therapy; VKA, vitamin K antagonists.

Currently, most patients with atrial fibrillation are treated with direct oral anticoagulants. The POINEER AF-PCI study (Open-Label, Randomized, Controlled, Multicenter Study Exploring Two Treatment Strategies of Rivaroxaban and a Dose-Adjusted Oral Vitamin K Antagonist Treatment Strategy in Subjects with Atrial Fibrillation who Undergo Percutaneous Coronary Intervention) tested the use of DAT with rivaroxaban $15 \mathrm{mg}$ once daily and clopidogrel versus TAT with rivaroxaban $2.5 \mathrm{mg}$ twice daily and aspirin and clopidogrel versus TAT with VKA and aspirin and clopidogrel. ${ }^{6}$ The primary endpoint TIMI bleeding at 1 year was significantly lower in DAT compared with TAT.

The RE-DUAL PCI study (Randomized Evaluation of Dual Antithrombotic Therapy with Dabigatran versus Triple Therapy with Warfarin in Patients with Nonvalvular Atrial Fibrillation Undergoing Percutaneous Coronary Intervention) compared TAT (VKA + aspirin + clopidogrel) for up to 3 months with DAT (dabigatran $2 \times 110$ or $150 \mathrm{mg}+$ clopidogrel or ticagrelor). ${ }^{7}$ Major or clinically relevant non-major bleeding was significantly lower in DAT $110 \mathrm{mg}$ or DAT $150 \mathrm{mg}$ versus TAT.

The AUGUSTUS (Antithrombotic Therapy After Acute Coronary Syndrome or PCI in Atrial Fibrillation) study tested two different regimens of DAT with apixaban $2 \times 5 \mathrm{mg}$ or VKA combined with clopidogrel or ticagrelor or prasugrel and two different regimens of TAT with apixaban $2 \times 5 \mathrm{mg}$ or VKA combined with aspirin and clopidogrel or ticagrelor or prasugrel. $^{8}$ In summary, major or clinically relevant nonmajor bleeding was lowest in the group with apixaban-DAT compared with VKA-DAT or the two TAT groups. Combination with aspirin was associated with higher bleeding risk in particular if treatment was longer than 30 days. $^{9}$
In the ENTRUST AF PCI (Edoxaban-based Dual Antithrombotic Therapy Noninferior to VKA-based Triple Therapy After $\mathrm{PCI}$ ) trial, DAT including edoxaban with clopidogrel or ticagrelor or prasugrel was compared with TAT with VKA, aspirin, and clopidogrel or ticagrelor or prasugrel. ${ }^{10}$ Major or clinically relevant non-major bleeding was noninferior in the DAT group compared with the TAT group.

These studies have changed recommendation for patients with indication for anticoagulation after coronary and peripheral revascularization. ${ }^{1,11}$ In addition, recent studies tested shorter duration of antiplatelet therapy after coronary intervention compared with longer duration. ${ }^{12}$

Evidence is limited to support a specific antithrombotic regimen for patients with an indication for oral anticoagulation and endovascular revascularization (EV) for peripheral arterial disease (PAD). There is no randomized trial available including patients after peripheral EV for PAD with indication for oral anticoagulation. Therefore, current guidelines recommend therapy according to PCI studies such as the previously discussed PIONEER, Re-DUAL, ENTRUST-AF, and AUGUSTUS trial. $^{6-10,13}$ As there are also limited data available for dualantiplatelet therapy after peripheral EV in general, duration of combined therapy should be as short as possible, depending on the clinical indication and bleeding risk. With the exception of below-the-knee stenting or complex lesions at very high risk of thrombosis, triple therapy should be discouraged. ${ }^{13}$

Management should be carefully assessed according to thrombotic risk versus bleeding risk. ${ }^{11}$ - Fig. 2 summarizes treatment duration for different clinical situations. In addition, gastric protection with a proton pump inhibitor is recommended and the dose intensity of oral anticoagulants should be carefully monitored. ${ }^{2,13}$ 


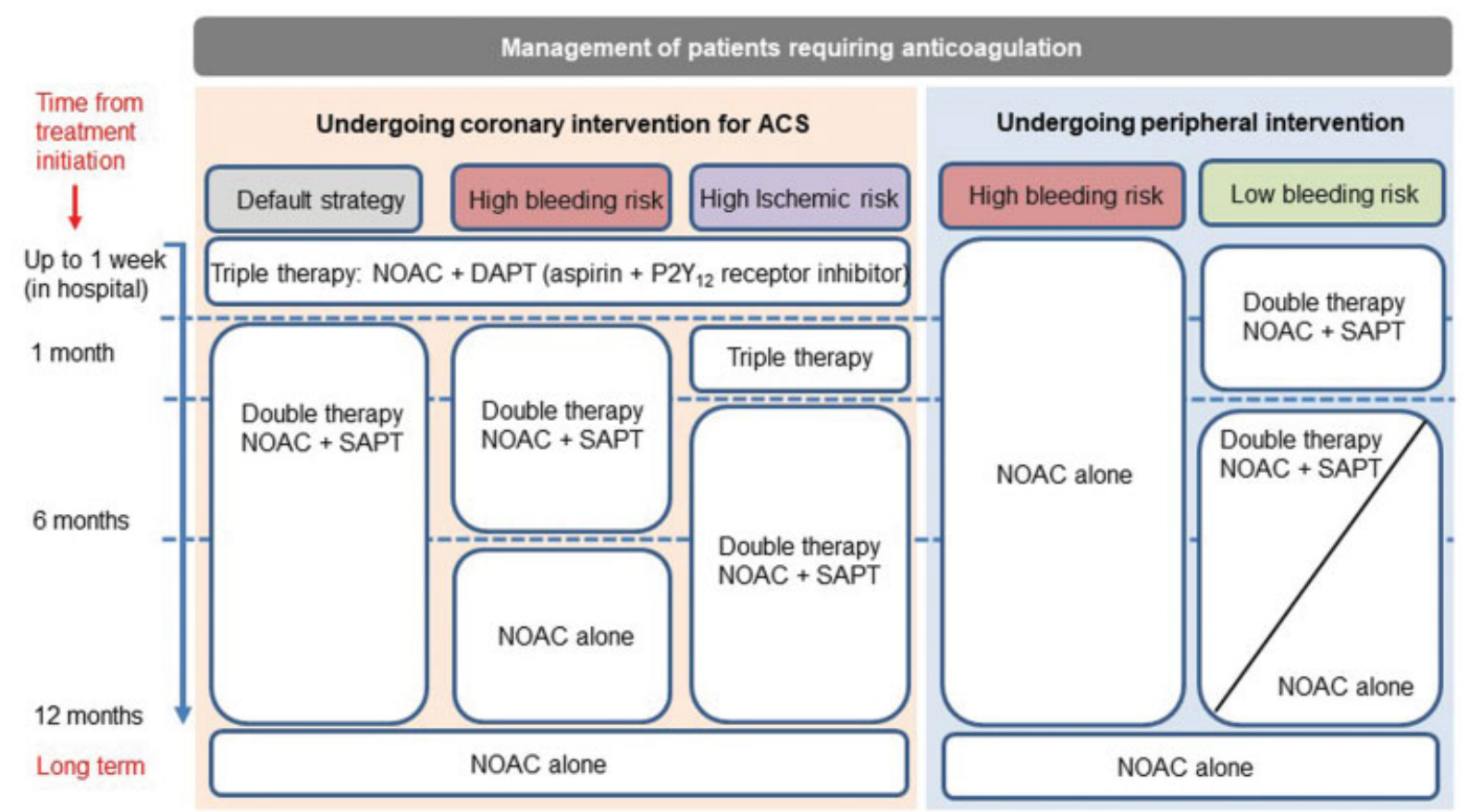

Fig. 2 Management of patients requiring anticoagulation undergoing coronary and peripheral anticoagulation. ${ }^{2,13}$ ACS, acute coronary syndrome; DAPT, dual-antiplatelet therapy; NOAC, non-vitamin K antagonist oral anticoagulant; SAPT, single-antiplatelet therapy.

\section{Combination of Antiplatelet and Anticoagulant Drugs for Risk Reduction in Patients with Atherosclerosis}

Patients with atherosclerosis in coronary or peripheral arteries are at increased risk of cardiovascular events. ${ }^{1,13}$ Antithrombotic medication is recommended in these patients because the risk of major adverse cardiovascular events (MACE; stroke, myocardial infarction, cardiovascular death) and major adverse limb events (MALE; major amputation, acute limb ischemia) is significantly reduced. ${ }^{1,13,14}$

The impact of more intensive antithrombotic therapy has been evaluated in different studies. For example, in the CHARISMA (Clopidogrel for High Atherothrombotic Risk and Ischemic Stabilization, Management, and Avoidance) trial, dual-antiplatelet therapy with aspirin $100 \mathrm{mg}$ and clopidogrel $75 \mathrm{mg}$ showed slight reduction of MACE in patients with symptomatic atherosclerotic diseases. ${ }^{15}$ The PEGASUS (Prevention of Cardiovascular Events in Patients with Prior Heart Attack Using Ticagrelor Compared with Placebo on a Background of Aspirin) study showed beneficial effect of long-term use of ticagrelor and aspirin more than 12 months after acute myocardial infarction. ${ }^{16}$ In this trial, there was also beneficial effect for the subgroup of patients with PAD for MACE and MALE. ${ }^{17}$ The TRA $2^{\circ} \mathrm{P}$ (Trial to Assess the Effects of Vorapaxar in Preventing Heart Attack and Stroke in Patients With Atherosclerosis) study tested the effect of vorapaxar on top of single- or dual-antiplatelet therapy in patients after myocardial infarction, stroke, or PAD. ${ }^{18,19}$ The stroke arm was stopped early because of adverse effects. There was a reduction in MACE (secondary endpoint) for patients after myocardial infarction or with
PAD, but there was a major increase in bleeding risk. In conclusion, more intensive antithrombotic therapy using multiple antiplatelet drugs reduces MACE and MALE events in patients with atherosclerosis, but the benefit is reduced by bleeding complications. ${ }^{15-20}$

Several years ago, the hypothesis that combination of antiplatelet and anticoagulant drugs may be beneficial in secondary prevention was tested with the combination of aspirin and the VKA warfarin. But studies such as the WAVE (Warfarin Antiplatelet Vascular Evaluation Trial) in PAD patients failed because they could not show reduction of events by major increase of bleeding risk. ${ }^{21}$

In patients with acute coronary syndrome, fondaparinux reduced major bleeding and mortality compared with enoxaparin on top of antiplatelet therapy (The Fifth Organization to Assess Strategies in Acute Ischemic Syndromes study). ${ }^{22}$ The combination of low-dose rivaroxaban and aspirin was first evaluated in the ATLAS ACS (Anti-Xa Therapy to Lower CV Events in Addition to Standard Therapy in Subjects with Acute Coronary Syndrome) TIMI 51 trial. ${ }^{23}$ In this study, more than 15,000 patients after acute coronary syndrome were treated with either placebo or rivaroxaban $2.5 \mathrm{mg}$ or rivaroxaban $5 \mathrm{mg}$ twice daily in combination with aspirin $100 \mathrm{mg}$. Rivaroxaban reduced risk for MACE by $16 \%$ and reduced stent thrombosis by $31 \%$. Major bleeding was significantly higher in the rivaroxaban groups, but no increase in fatal bleeding occurred, especially in the very low dose group.

This concept was tested for patients with stable atherosclerosis in the COMPASS (Cardiovascular OutcoMes for People Using Anticoagulation StrategieS) study. COMPASS tested the combination of aspirin and low-dose rivaroxaban 
Table 2 Recommendations of current guidelines for dual-pathway anticoagulation ${ }^{1,28-30}$

\begin{tabular}{|c|c|c|}
\hline Recommendations & Class & Level of evidence \\
\hline \multicolumn{3}{|l|}{2019 ESVM guidelines on the management of PAD ${ }^{28}$} \\
\hline $\begin{array}{l}\text { The combined therapy of aspirin } 100 \mathrm{mg} \text { od and rivaroxaban } 2.5 \mathrm{mg} \text { bid should be } \\
\text { considered in PAD patients without a high risk of bleeding, or other contraindications }\end{array}$ & Ila & B \\
\hline \multicolumn{3}{|l|}{2019 ESC-EASD guidelines on diabetes, pre-diabetes, and cardiovascular diseases ${ }^{30}$} \\
\hline $\begin{array}{l}\text { In patients with diabetes and chronic symptomatic LEAD without high bleeding risk, a } \\
\text { combination of low-dose rivaroxaban ( } 2.5 \mathrm{mg} \text { bid) and aspirin ( } 100 \mathrm{mg} \text { od) should be } \\
\text { considered }\end{array}$ & Ila & B \\
\hline \multicolumn{3}{|l|}{2019 ESC guidelines on the management of chronic coronary syndromes ${ }^{1}$} \\
\hline $\begin{array}{l}\text { Adding a second antithrombotic drug to aspirin for long-term secondary prevention should } \\
\text { be considered in patients with a high risk of ischemic events }{ }^{\mathrm{a}} \text { and without high bleeding risk }\end{array}$ & Ila & A \\
\hline $\begin{array}{l}\text { Adding a second antithrombotic drug to aspirin for long-term secondary prevention may be } \\
\text { considered in patients with at least a moderately increased risk of ischemic events and } \\
\text { without high bleeding risk }\end{array}$ & IIb & A \\
\hline
\end{tabular}

${ }^{a}$ Diffuse multivessel coronary artery disease with at least one of the following: diabetes mellitus requiring medication, recurrent myocardial infarction, peripheral arterial disease, or chronic kidney disease with estimated glomerular filtration rate of 15 to $59 \mathrm{~mL} / \mathrm{min} / 1.73 \mathrm{~m}$.

\section{Combination of antiplatelet and anticoagulant drugs}

\section{Balance between thrombosis and bleeding}
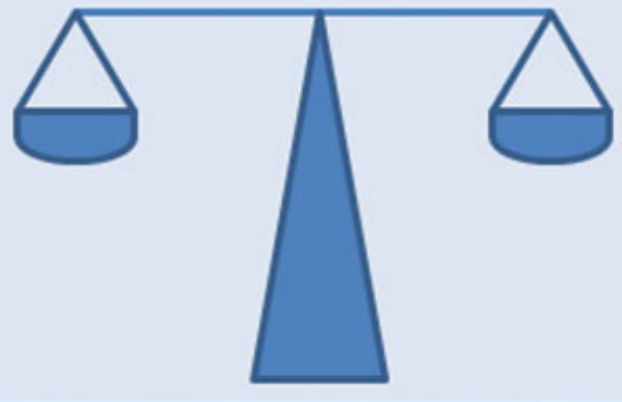

\section{Patients with indication for long-term anticoagulation}

- Atrial fibrillation

- Venous thromboembolism

Temporary combination of NOAC* with

DAPT or SAPT after revascularisation

- Apixaban $5 \mathrm{mg}$ bd

- Edoxaban $60 \mathrm{mg}$ od

- Rivaroxaban $15 \mathrm{mg}$ od

- Dabigatran $110 / 150 \mathrm{mg}$ bd

Fig. 3 Summary slide about combination of antiplatelet and anticoagulant drugs. *Dosage according to drug admission. DAPT, dual-antiplatelet therapy; NOAC, non-vitamin K antagonist oral anticoagulant; SAPT, single-antiplatelet therapy. 
$(2 \times 2.5 \mathrm{mg})$ in patients with coronary artery disease, PAD, and carotid artery stenosis (CAS). ${ }^{24}$ There was a significant reduction of MACE in the hole group of 27,395 study patients. A subgroup analysis including the 4,129 patients with peripheral atherosclerosis (PAD or CAS) showed a significant reduction of both MACE and MALE events. ${ }^{25}$ As expected, the combination therapy results in a significant increase in major bleeding compared with placebo, but the positive effects outweigh these side effects.

In the COMPASS study, patients with peripheral and polyvascular atherosclerosis could be identified as high-risk population. The VOYAGER PAD (Vascular Outcomes Study of ASA Along With Rivaroxaban in Endovascular or Surgical Limb Revascularization for Peripheral Artery Disease) study included only PAD patients after peripheral revascularization. This study is a randomized trial including 6,564 patients after successful surgical or endovascular lower extremity revascularization. ${ }^{26}$ All patients received aspirin $100 \mathrm{mg}$ and were randomized to rivaroxaban $2.5 \mathrm{mg}$ twice daily or placebo. After a follow-up period of 3 years, the primary efficacy endpoint (MACE or MALE) was significantly decreased using low-dose rivaroxaban compared with placebo mostly triggered by reduction of acute limb ischemia. There was no significant difference in the primary safety outcome (TIMI major bleeding) which occurred in $2.7 \%$ in the rivaroxaban group and in $1.9 \%$ in the placebo group $(p=0.07)$. Additional treatment with clopidogrel $75 \mathrm{mg}$ was allowed for up to 6 months. There was no significant difference between treatment groups in the subgroup of patients using clopidogrel $75 \mathrm{mg} .{ }^{27}$ Patients who received clopidogrel on top of aspirin and low-dose rivaroxaban for more than 30 days had major increase of bleeding complications. ${ }^{27}$

In conclusion, the COMPASS study showed a significant reduction of cardiovascular and limb events with the combination of low-dose rivaroxaban and aspirin in patients with atherosclerosis in different vascular territories. In the VOYAGER PAD study, MACE and MALE events were significantly reduced by the combination of these antiplatelet and antithrombotic medications in patients after peripheral revascularization. Bleeding risk must be kept in mind especially gastrointestinal bleeding in the first months of treatment, but for the long term, beneficial effects overweigh the initial risk in most patients. Therefore, recent guidelines recommend the combination of aspirin and low rivaroxaban especially for patients with high risk for cardiovascular events and low bleeding risk ${ }^{1,28-30}$ (-Table 2).

\section{Combination of Antiplatelet and Anticoagulant Drugs for Rare Indications}

A combination of antiplatelet and anticoagulant drugs can be used in patients with severe APS by individual decision. Usually, VKAs at therapeutic intensity (INR range of 2-3) are the standard treatment for thrombotic APS. ${ }^{31}$ In patients with recurrent arterial thrombosis despite adequate treatment, after evaluating for other potential causes, an increase of INR target to 3 to 4 or addition of low-dose aspirin can be discussed. $^{31}$

\section{Conclusions}

Combination of antiplatelet and anticoagulant drugs is useful in different indications ( - Fig. 3). In patients with indication for anticoagulation, addition of an antiplatelet can be necessary for several months after coronary or peripheral intervention. In high-risk patients with atherosclerosis, low-dose rivaroxaban and aspirin improved prognosis by reduction of MACE and MALE events. Each combination of antiplatelet and anticoagulant drugs increases bleeding risk. Therefore, indication and duration of combined antiplatelet and anticoagulant drugs must be assessed carefully under weighing of thrombotic and bleeding risk.

\section{Conflict of Interest}

Honoraria for lectures or advisory boards from Amarin Germany GmbH, Amgen GmbH, Bayer Health Care, Boehringer Ingelheim, Bristol-Myers Squibb, Daiichi Sankyo, Leo Pharma, MSD Sharp \& Dohme, Novartis Pharma, Pfizer Pharma GmbH, Sanofi-Aventis GmbH.

\section{References}

1 Knuuti J, Wijns W, Saraste A, et al; ESC Scientific Document Group. 2019 ESC Guidelines for the diagnosis and management of chronic coronary syndromes. Eur Heart J 2020;41(03):407-477

2 Collet JP, Thiele H, Barbato E, et al; ESC Scientific Document Group. 2020 ESC Guidelines for the management of acute coronary syndromes in patients presenting without persistent ST-segment elevation. Eur Heart J 2021;42(14):1289-1367

3 Hindricks G, Potpara T, Dagres N, et al; ESC Scientific Document Group. 2020 ESC Guidelines for the diagnosis and management of atrial fibrillation developed in collaboration with the European Association for Cardio-Thoracic Surgery (EACTS): The Task Force for the diagnosis and management of atrial fibrillation of the European Society of Cardiology (ESC) Developed with the special contribution of the European Heart Rhythm Association (EHRA) of the ESC. Eur Heart J 2021;42(05):373-498

4 Dewilde WJ, Oirbans T, Verheugt FW, et al; WOEST Study Investigators. Use of clopidogrel with or without aspirin in patients taking oral anticoagulant therapy and undergoing percutaneous coronary intervention: an open-label, randomised, controlled trial. Lancet 2013;381(9872):1107-1115

5 Fiedler KA, Maeng M, Mehilli J, et al. Duration of triple therapy in patients requiring oral anticoagulation after drug-eluting stent implantation: the ISAR-TRIPLE trial. J Am Coll Cardiol 2015;65 (16):1619-1629

6 Gibson CM, Mehran R, Bode C, et al. Prevention of bleeding in patients with atrial fibrillation undergoing PCI. N Engl J Med 2016;375(25):2423-2434

7 Cannon CP, Bhatt DL, Oldgren J, et al; RE-DUAL PCI Steering Committee and Investigators. Dual antithrombotic therapy with dabigatran after PCI in atrial fibrillation. N Engl J Med 2017;377 (16):1513-1524

8 Lopes RD, Heizer G, Aronson R, et al; AUGUSTUS Investigators. Antithrombotic therapy after acute coronary syndrome or PCI in atrial fibrillation. N Engl J Med 2019;380(16):1509-1524

9 Alexander JH, Wojdyla D, Vora AN, et al. Risk/Benefit tradeoff of antithrombotic therapy in patients with atrial fibrillation early and late after an acute coronary syndrome or percutaneous coronary intervention: insights from AUGUSTUS. Circulation 2020;141(20):1618-1627

10 Vranckx P, Lewalter T, Valgimigli M, et al. Evaluation of the safety and efficacy of an edoxaban-based antithrombotic regimen in patients 
with atrial fibrillation following successful percutaneous coronary intervention $(\mathrm{PCI})$ with stent placement: rationale and design of the ENTRUST-AF PCI trial. Am Heart J 2018;196:105-112

11 Rodriguez F, Harrington RA. Management of antithrombotic therapy after acute coronary syndromes. N Engl J Med 2021; 384(05):452-460

12 Valgimigli M, Frigoli E, Heg D, et al; MASTER DAPT Investigators. Dual antiplatelet therapy after PCI in patients at high bleeding risk. N Engl J Med 2021;385(18):1643-1655

13 Aboyans V, Ricco JB, Bartelink MEL, et al; ESC Scientific Document Group. 2017 ESC Guidelines on the Diagnosis and Treatment of Peripheral Arterial Diseases, in collaboration with the European Society for Vascular Surgery (ESVS): Document covering atherosclerotic disease of extracranial carotid and vertebral, mesenteric, renal, upper and lower extremity arteries Endorsed by: the European Stroke Organization (ESO) The Task Force for the Diagnosis and Treatment of Peripheral Arterial Diseases of the European Society of Cardiology (ESC) and of the European Society for Vascular Surgery (ESVS). Eur Heart J 2018;39(09):763-816

14 Antithrombotic Trialists' Collaboration. Collaborative meta-analysis of randomised trials of antiplatelet therapy for prevention of death, myocardial infarction, and stroke in high risk patients. BMJ 2002;324(7329):71-86

15 Bhatt DL, Fox KAA, Hacke W, et al; CHARISMA Investigators. Clopidogrel and aspirin versus aspirin alone for the prevention of atherothrombotic events. N Engl J Med 2006;354(16):1706-1717

16 Bonaca MP, Bhatt DL, Cohen M, et al; PEGASUS-TIMI 54 Steering Committee and Investigators. Long-term use of ticagrelor in patients with prior myocardial infarction. N Engl J Med 2015; 372(19):1791-1800

17 Bonaca MP, Bhatt DL, Storey RF, et al. Ticagrelor for prevention of ischemic events after myocardial infarction in patients with peripheral artery disease. J Am Coll Cardiol 2016;67(23): 2719-2728

18 Morrow DA, Braunwald E, Bonaca MP, et al; TRA 2P-TIMI 50 Steering Committee and Investigators. Vorapaxar in the secondary prevention of atherothrombotic events. N Engl J Med 2012;366(15): 1404-1413

19 Bonaca MP, Scirica BM, Creager MA, et al. Vorapaxar in patients with peripheral artery disease: results from TRA2degreesP-TIMI 50. Circulation 2013;127(14):1522-1529, 1529e1-6

20 Savarese G, Reiner MF, Uijl A, et al. Antithrombotic therapy and major adverse limb events in patients with chronic lower extremity arterial disease: systematic review and meta-analysis from the European Society of Cardiology Working Group on
Cardiovascular Pharmacotherapy in Collaboration with the European Society of Cardiology Working Group on Aorta and Peripheral Vascular Diseases. Eur Heart J Cardiovasc Pharmacother 2020;6(02):86-93

21 Anand S, Yusuf S, Xie C, et al; Warfarin Antiplatelet Vascular Evaluation Trial Investigators. Oral anticoagulant and antiplatelet therapy and peripheral arterial disease. N Engl J Med 2007;357 (03):217-227

22 Yusuf S, Mehta SR, Chrolavicius S, et al; Fifth Organization to Assess Strategies in Acute Ischemic Syndromes Investigators. Comparison of fondaparinux and enoxaparin in acute coronary syndromes. N Engl J Med 2006;354(14):1464-1476

23 Mega JL, Braunwald E, Wiviott SD, et al; ATLAS ACS 2-TIMI 51 Investigators. Rivaroxaban in patients with a recent acute coronary syndrome. N Engl J Med 2012;366(01):9-19

24 Eikelboom JW, Connolly SJ, Bosch J, et al; COMPASS Investigators. Rivaroxaban with or without aspirin in stable cardiovascular disease. N Engl J Med 2017;377(14):1319-1330

25 Anand SS, Bosch J, Eikelboom JW, et al; COMPASS Investigators. Rivaroxaban with or without aspirin in patients with stable peripheral or carotid artery disease: an international, randomised, double-blind, placebo-controlled trial. Lancet 2018;391 (10117):219-229

26 Bonaca MP, Bauersachs RM, Anand SS, et al. Rivaroxaban in peripheral artery disease after revascularization. $\mathrm{N}$ Engl J Med 2020;382(21):1994-2004

27 Hiatt WR, Bonaca MP, Patel MR, et al. Rivaroxaban and aspirin in peripheral artery disease lower extremity revascularization: impact of concomitant clopidogrel on efficacy and safety. Circulation 2020;142(23):2219-2230

28 Frank U, Nikol S, Belch J, et al. ESVM guideline on peripheral arterial disease. Vasa 2019;48(Suppl 102):1-79

29 Aboyans V, Bauersachs R, Mazzolai L, et al. Antithrombotic therapies in aortic and peripheral arterial diseases in 2021: a consensus document from the ESC working group on aorta and peripheral vascular diseases, the ESC working group on thrombosis, and the ESC working group on cardiovascular pharmacotherapy. Eur Heart J 2021;42(39):4013-4024

30 Cosentino F, Grant PJ, Aboyans V, et al; ESC Scientific Document Group. 2019 ESC Guidelines on diabetes, pre-diabetes, and cardiovascular diseases developed in collaboration with the EASD. Eur Heart J 2020;41(02):255-323

31 Sayar Z, Moll R, Isenberg D, Cohen H. Thrombotic antiphospholipid syndrome: a practical guide to diagnosis and management. Thromb Res 2021;198:213-221 